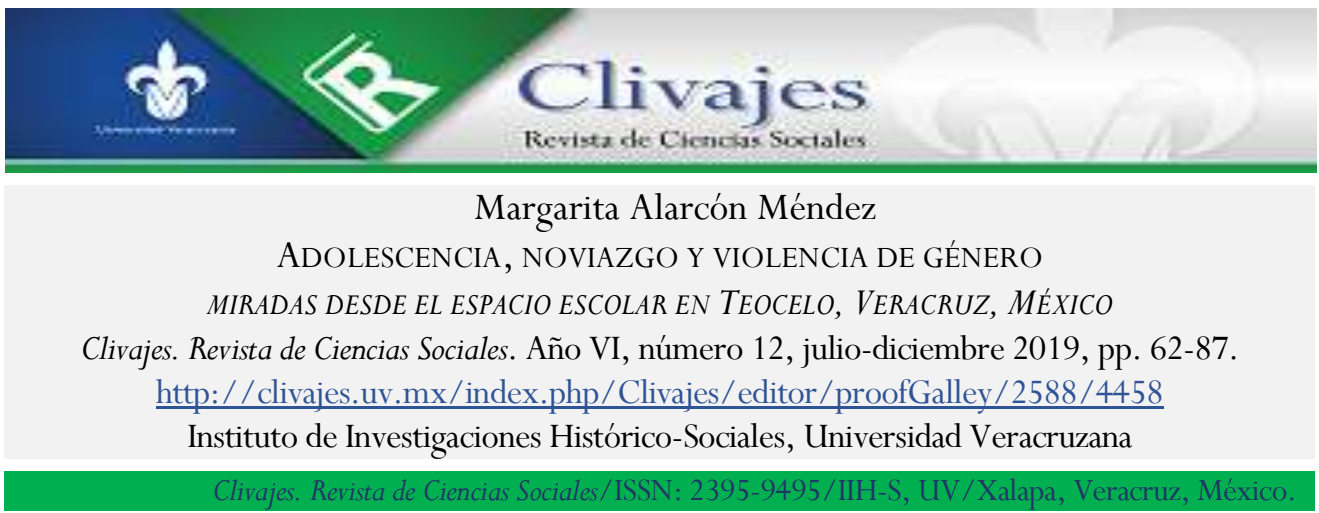

Recibido: 04/09/2019

Aceptado: 15/09/2019

Publicación: 14/11/2019 


\title{
ADOLESCENCIA, NOVIAZGO Y VIOLENCIA DE GÉNERO Miradas desde el espacio escolar en Teocelo, Veracruz, México
}

\author{
Margarita Alarcón Méndez $\dagger^{*}$
}

\section{Resumen}

En este ensayo se explica en qué consisten los conceptos género, adolescencia y violencia y cómo se vinculan entre sí. Resulta complejo estudiar la violencia de género durante el noviazgo y específicamente en esta etapa de la vida, motivo por el cual explicaré el enfoque de género y su finalidad, entendiendo esta categoría en su relación con el noviazgo entre los adolescentes, quienes evidencian las prácticas aprendidas, que "deben" llevar a cabo: como dejar de tener amigos del sexo opuesto porque la pareja se puede molestar, lo cual nos lleva a la violencia en el noviazgo, esto es, de acuerdo con Pereira (2012, pp. 55-56), cualquier acción o conducta basada en el género que cause muerte, daño o sufrimiento físico, sexual o psicológico a la mujer o el hombre a través de mecanismos de violencia, físicos y/o psicológicos.

Palabras clave: Género, Noviazgo, Adolescencia, Violencia

\section{EL ENFOQUE GÉNERO}

La historia del pensamiento feminista es una historia del rechazo de la jerarquía varón-mujer, y el término género forma parte de una tentativa para explicar la desigualdad entre mujeres y hombres.

SCOTT, 1990

Para Marta Lamas (2000), lo masculino y femenino han sido construidos histórica y culturalmente, lo cual explica los discursos sociales que asumen como "natural" que el hombre sea el más fuerte o que la mujer desee ser madre. Lo que define al género es la acción simbólica colectiva; es el orden simbólico social lo que configura la idea de lo que deben ser hombres y mujeres. El género ${ }^{1}$ se ha construido mediante saberes hegemónicos

\footnotetext{
* Publicamos este ensayo de la psicóloga y maestra en Ciencias Sociales (Uv) Margarita Alarcón Méndez, como homenaje a su breve pero fructífera vida, y como una muestra de las preocupaciones sociales de una joven investigadora abatida por la violencia en su natal Huatusco, la noche del 11 de junio de 2019 (RIP).

${ }^{1}$ Según la historiadora Joan Scott (1990), el género comprende cuatro elementos interrelacionados: 1) Símbolos culturales disponibles que evocan representaciones múltiples (y a menudo contradictorias). Eva y María, por ejemplo, como símbolos de la mujer en la tradición cristiana occidental - pero también mitos de luz y oscuridad, de purificación y contaminación, inocencia y corrupción. 2) Conceptos normativos que manifiestan las interpretaciones de los significados de los símbolos, en un intento de limitar y contener sus posibilidades metafóricas. Dichos conceptos se expresan en doctrinas religiosas, educativas, científicas, legales y políticas, que afirman categórica y unívocamente lo masculino y femenino. 3) Romper con la noción de fijeza, es decir, no dar por hecho que las posiciones normativas fueron producto del consenso social y siempre han sido así. Lo cual conducirá a la búsqueda del género como hecho histórico y no natural. 4) Identidad subjetiva. Las formas en que se construyen las identidades genéricas tomando como base la dimensión histórica (pp. 289-291).
} 
como la religión, la ciencia, la medicina, la filosofía, etc., los cuales reproducen discursos legitimadores de relaciones desiguales (Mayobre, 2006, p. 25). La cultura marca con etiquetas genéricas a los seres humanos y el género marca la percepción de todo lo demás: lo social, lo político, lo religioso, lo cotidiano, todo se configura a través de (o gracias a) la lógica del género, misma que reproduce relaciones de poder.

Hablar de género incluye hablar del patriarcado, entendido como sistema de pactos interclasistas entre varones que ha mantenido a las mujeres apartadas del poder a través de mecanismos ideológicos que se incrustan en la conciencia y escapan al control de la razón; tal es el caso de los estereotipos de género (Cobo, 1995, pp. 61-62). El sistema patriarcal echa mano de todo lo que halla a su alcance para reproducirse: medios de comunicación, música, literatura, educación, familia, etc. Se trata de un sistema tan naturalizado, que logra que las mujeres deseen aquello que se exige de ellas -por ejemplo, la belleza-; los costos económicos y emocionales de esto dejan estragos en miles de mujeres. ${ }^{29}$

El propósito de los estudios de género es desmontar el prejuicio de que la biología determina "lo femenino", obviando aspectos sociales y culturales (Cobo, 1995, p. 55). Es necesario poner de manifiesto que las actividades que desempeñan las mujeres no tienen una raíz biológica, sino social. Asumir que las mujeres son como son por "naturaleza" implicaría otorgarle cierta fijeza a sus acciones, las cuales serían imposibles de modificar porque formaría parte de su biología, cuestión, en realidad, falaz. El enfoque social permite dar cuenta de que el género es una construcción sujeta a cambios $-\mathrm{y}$, a su vez, productora de cambios-, capaz de otorgar formas de vida diferentes.

Es primordial analizar los efectos del patriarcado en todas las esferas y estratos de la sociedad, entendiendo por patriarcado -como mencioné antes- el sistema de pactos interclasistas entre varones cuyo eje es la subordinación femenina y cuya base es la inmanencia biológica (Cobo, 1995, p. 61). La categoría género, como señala Rodríguez (2000, p. 117), permite analizar las relaciones de poder entre hombres y mujeres, y ayuda a explicar por qué la desigualdad entre los sexos tiene una base cultural y no natural. La importancia de los estudios de género radica en la posibilidad de analizar situaciones y problemáticas habituales desde una perspectiva psicológica o social; sin

\footnotetext{
${ }^{2}$ De acuerdo con la Sociedad Internacional de Cirugía Plástica y Estética (ISAPS, por sus siglas en inglés), México ocupa el quinto lugar a escala mundial por el número de intervenciones cosméticas, bajo la premisa de que la belleza es un medio para obtener cosas (empleo, matrimonio). De los pacientes que solicitan cirugía estética, $80 \%$ son mujeres, de las cuales entre $12 \%$ y 15\% son aún adolescentes (La Jornada, 2012). Esto refleja claramente la construcción de la identidad femenina en la civilización occidental, donde las mujeres han sido objetualizadas y cosificadas, minimizando su capacidad para nombrar y significar el mundo (Mayobre, 2006, p. 24).
} 
embargo, el enfoque de género es clave para comprender a profundidad la conducta humana en la cotidianidad.

Un ejemplo ilustrativo al respecto es el alcoholismo: desde una mirada psicológica, que un hombre sea alcohólico puede deberse a problemas familiares, a dificultades en el manejo de las emociones o incluso a que la figura paterna sea alcohólica también; desde una mirada social, se agregan a ello elementos como la influencia de los pares, la utilización del alcohol como medio de socialización, y hasta los medios de comunicación, los cuales otorgan cierto estatus a quienes consumen bebidas alcohólicas. Si utilizamos el sistema de género en el análisis, éste se vuelve más completo, ya que se puede consumir alcohol para demostrar hombría. Se puede observar que los hombres gozan de mayor libertad para llorar cuando están bajo los efectos del alcohol; sobrios, dicha conducta "no está permitida" debido a que "deben ser fuertes".

Otro ejemplo evidente: cuando una mujer vive violencia en el noviazgo, se puede asumir, desde una mirada psicológica, que ella reproduce lo que vivió, es decir, seguro su papá era violento con su mamá y ella aprendió que ese comportamiento era natural; desde una perspectiva social, es posible que no deje a su pareja porque no quiere estar sola o incluso porque se ha acostumbrado a esa dinámica de la relación. Con las aportaciones de los estudios de género, se comprende que no sólo hay un elemento implicado en que ella continúe en la relación. La violencia es estructural, porque ella teme que él sea agresivo si ella lo deja; esto, aunado a que la última vez que intentó dejarlo, él "se puso mal” y empezó a tomar, por lo que ella sintió culpa (su rol de cuidadora) y volvió con él.

Cobo (1995, pp. 61-62) enfatiza la percepción de que las mujeres son tiernas por naturaleza. Al respecto, el género analiza los roles asignados a mujeres y hombres por el hecho de serlo, es decir, por su naturaleza, y eso facilita su asimilación y reproducción; sin embargo, esto no necesariamente debe ser así, puede ser diferente. La categoría género, como señala Rodríguez (2000, p. 117), permite analizar las relaciones de poder entre hombres y mujeres, y ello aporta una visión integradora desde la cual se asume que hombres y mujeres ejercen el poder de diversas formas, desde distintos espacios y con diferentes fines.

El género, eje clave en el análisis de la conducta, interactúa con otras categorías: raza, etnia, clase, edad, sexualidad, amor, y busca cuestionar los marcos establecidos para agregar nuevas miradas e interpretaciones a la conducta misma. Cada persona tiene un lugar en el mundo, por lo cual sus experiencias/vivencias son situadas, lo cual es un elemento que el género toma en cuenta: el conocimiento de la persona es situado, es 
decir, una conducta y su análisis no puede universalizarse (Blázquez, 2008, p. 29). Como señala Joan Scott (1990, p. 275), el género afecta a aquellas esferas de la vida que no parecen vinculadas con él. En este eje, la sexualidad es una de las esferas más fascinantes para estudiar la plasticidad del comportamiento humano (Córdova, 2013).

\section{CUERPO Y SEXUALIDAD}

La sexualidad engloba una serie de conductas clasificadas, desde una mirada moral, como adecuadas e inadecuadas; en la clasificación de dichas conductas el género es clave, porque diferencia entre conductas aceptables e inaceptables para mujeres y hombres. La sexualidad se entiende como "un conjunto de tipos específicos de experiencias eróticas y reproductivas posibles en una sociedad determinada, se encuentra configurada por relaciones sociales que van más allá de ella, pero de las cuales es signo y referente a la vez" (Córdova, 2003). La sexualidad es una construcción histórica que implica una serie de creencias, relaciones e identidades relativas al cuerpo de los sujetos socialmente construidas, su interpretación dependerá del contexto socio-cultural (Martínez y Solís 2009, p. 151). La sexualidad implica elementos asociados con los sujetos y sus prácticas, tales como fantasías, creencias, normas morales sobre los usos del cuerpo, sentimientos (Córdova, 2003).

La sexualidad, como señala Córdova (2003): abarca diversas normas "naturales", entre las cuales se debe elegir afectivamente a una persona del sexo opuesto; asimismo, la sexualidad crea una norma "implícita" sobre cuáles son las conductas adecuadas para cada edad, para la formación de parejas, el ejercicio de la vida sexual, sobre la edad adecuada para iniciar un noviazgo y tener hijos, acerca de la valoración positiva o negativa del sexo no procreativo, homosexual, heterosexual o fuera del lazo conyugal, todo ello con una clara diferenciación entre mujeres y hombres.

En la sexualidad se incrustan y legitiman relaciones de poder que rigen quién tiene derecho a hacer qué a quién, de acuerdo con el papel que cada uno desempeña en la estructura social. Asimismo incluye un sistema de valores que varía para hombres y mujeres, quedando estas últimas en desventaja. Ante dicho sistema de valores, hay resistencias entre las personas, que no siempre se adecuan al modelo hegemónico de la sexualidad, esto es, un eje en disputa que evidencia luchas y resistencias hacia los controles sociales (Córdova, 2003).

Para Godelier (citado por Solís y Martínez, 2014, p. 167): "la sexualidad es el lugar privilegiado del cuerpo donde se unen la lógica de los individuos y la lógica de la 
sociedad, donde se incorporan ideas, imágenes, símbolos, deseos, e intereses opuestos”. La sexualidad implica todo lo correspondiente a los usos del cuerpo, por lo cual se vuelve un eje amplio que resulta clave para entender las relaciones de pareja durante la adolescencia.

\section{LA ADOLESCENCIA: ETAPA CLAVE PARA EL ANÁLISIS DEL NOVIAZGO}

La adolescencia es una etapa importante por los cambios físicos, mentales, emocionales y sociales que atraviesa la persona, lo cual repercute en su comportamiento y su percepción del entorno y afecta la conformación de su identidad. La importancia de este periodo radica en que es cuando las y los adolescentes afinan su mirada sobre la organización genérica de la sociedad que habitan (Sosa, Erviti y Menkes, 2012, p. 257).

Desde una mirada biológica, el cuerpo de la y el adolescente cambian: la aparición de la menstruación y la maduración de los órganos sexuales se traduce en el desarrollo de los senos, el crecimiento de los genitales y del vello púbico y axilar en las mujeres, y en los hombres crecen los genitales, la masa muscular y el vello corporal. Existe un amplio rango de edad en el que se manifiestan dichos cambios (Papalia, Feldman y Martorell, 2012, p. 355).

Para Sosa et al. (2012, pp. 285-286), la visibilidad de los cambios corporales se refleja en cambios sociales, es decir, en la forma como las y los adolescentes son tratados: los cuerpos de las adolescentes son cosificados y evaluados de acuerdo con el criterio de belleza hegemónico, mientras que los cuerpos de los hombres son jerarquizados de acuerdo con su "fortaleza" y el acatamiento de la heteronormatividad. En la adolescencia se intensifican las estrategias dirigidas a moldear la identidad de género, con la adquisición y reproducción de comportamientos ligados a lo masculino y lo femenino.

Cabe decir que en las sociedades preindustriales no existía el concepto de adolescencia: se solía considerar que los niños eran adultos cuando maduraban físicamente. De acuerdo con la cultura, la adolescencia va tomando diferentes formas, se identifica como un periodo de "descanso" del mundo adulto, en el cual los adolescentes pasan buena parte de su tiempo en su propio mundo (Papalia, et. al, 2012, p. 354).

La noción que tenemos actualmente sobre adolescencia y juventud es relativamente reciente en México y otros países Iberoamericanos. La construcción de la persona "joven" data de poco más de un siglo y es resultado de muchos cambios, pues ha sido diferente según el momento de la historia del que se hable. La juventud se ha conformado a través del tiempo y el contexto que ha permitido el surgimiento de una 
realidad empírica diferente a la niñez y la etapa adulta (Castro y Sáenz, 2011).

La diferencia entre la juventud y otra etapa es que está entre los márgenes movedizos de la independencia infantil y la autonomía de los adultos; en el margen de una fase de separación de la esfera privada de la familia y una esfera de agregación a la vida adulta. Por ello, la adolescencia es un estadio inevitable de desarrollo humano, caracterizada por momentos de crisis, de despertar del sentido social, de la emotividad (amor y amistad), la consciencia, etc., cuyas características se contraponen al mundo adulto, siendo la adultez una etapa claramente definida y estable (Castro y Sáenz, 2011).

Cada sociedad ha creado y representado una definición de los jóvenes de acuerdo con su momento histórico, legitimando estereotipos y haciéndolos circular con base en preceptos y prácticas cotidianas. Una de las consecuencias de dichos estereotipos es la representación dual de la juventud como una amenaza e intrínsecamente mala o como foco de esperanza y optimismo e intrínsecamente buena, aunque vulnerable. Lo anterior da como resultado que se les considere incontrolables, por lo cual es necesario moldearlos para que puedan llegar a ser "respetables" (Castro y Sáenz, 2011).

El discurso adulto sobre la adolescencia está lleno de connotaciones negativas; madres, padres, profesores y profesoras se relacionan con los jóvenes de una manera ambigua, porque no hay un canal de comunicación eficiente entre unos y otros. De ahí que la vigilancia sea un asunto clave para entender el vínculo jerárquico entre los dos mundos: el adulto y el adolescente. Las principales funciones de la vigilancia son establecer una relación de poder, evitar embarazos no planeados, estar alerta con respecto a las conductas de las y los adolescentes para supervisar si cumplen las expectativas, es decir, si se portan bien, acuden a la escuela, cuidan su imagen social, entre otras (Castro y Sáenz, 2011).

En el pensamiento común, existe la construcción social de que el conocimiento llega con la edad; desde esa lógica, la sabiduría corresponde a los mayores, y ello les otorga poder sobre la juventud/adolescencia, lo cual se ve reflejado en la imposición de límites para producir un orden en el cual cada quien debe ocupar su lugar (Bourdieu, 2002, p. 164). Los adultos creen que deben preparar y moldear a las y los adolescentes para la esfera pública, y elaboran una lista implícita de conductas permitidas. Por lo contrario, la persona adulta es concebida como una persona superior. Esta situación asimétrica le otorga privilegios, a esto se le conoce como adultocentrismo, el cual es aprendido en el hogar y reforzado en el mundo exterior (escuela, grupos sociales, medios de comunicación, etc.). Dicha situación genera que las y los adolescentes 
quieran ser adultos para gozar de privilegios que no tienen (UNICEF, 2013).

La idea de edad social permite observar a la adolescencia como un grupo social posicionado y construido históricamente. Se entenderá por edad social una serie de derechos, privilegios, deberes y formas de actuar, es decir, se define a partir de la diversidad de momentos históricos significativos: el matrimonio, la transición a la secundaria (Duarte 2012, cit. por López, 2014, p. $14)$.

La adolescencia como grupo social es sometida por el adultocentrismo, el cual se entiende como una relación de dominación determinada por la edad social. El adultocentrismo es un constructo histórico-social que ha definido relaciones sociales asimétricas, enmarcadas en lógicas autoritarias (López, 2014, p. 15). En las sociedades primitivas que carecían de Estado, los jóvenes debían cumplir ritos de paso para tener acceso a la vida adulta; dichos ritos tenían como eje clave la edad.

Al respecto, es necesario tener presente que los sistemas de edades legitiman desigualdades con base en jerarquizaciones y subordinaciones (Fleixa, 1998, cit. por López, 2014, p. 15). La juventud surge bajo un marco histórico de subordinación, marginación y limitaciones; se erige como una edad social dependiente de las clases dominantes: aquellos de mayor edad (López, 2014, p. 16), quienes rigen el funcionamiento económico y político de la organización societal (Duarte, 2012, cit. por López, 2014, p.16).

Para consolidar el control sobre la adolescencia/juventud se le restó presencia activa en la sociedad, generando un fenómeno adultocéntrico denominado "invisibilidad de la juventud/adolescencia”, lo cual demuestra la constitución histórica de la juventud bajo un molde de relación en sociedad, al que se le otorgó una posición de subordinación social (López, 2014, p. 16). Las clasificaciones por edad (y también por sexo y/o por clase) vienen a ser siempre una forma de imponer límites, de producir un orden en el cual cada quien debe mantenerse, donde cada quien debe ocupar su lugar. La juventud y la vejez no están dadas, sino que se construyen socialmente (Bourdieu, 2002, p. 164); en esta construcción, la adolescencia/juventud queda en desventaja y debe adecuarse a los lineamientos construidos por el mundo adulto.

La adolescencia es una etapa de tránsito en la vida, que adquiere valor en la medida en que está referida al mundo adulto y su importancia consiste en que en un momento dado se llegará a ser adulto (Vásquez, 2013, p. 221). En este sentido, el adultocentrismo remite a cualquier comportamiento, acción o lenguaje que limite o ponga en duda las capacidades de las y los adolescentes, siempre en función de su edad. 
Entre los mensajes más comunes se encuentran frases como "cuando seas grande puedes dar tu opinión"; “cuando tú vas, yo vengo de vuelta”; "es mejor que las decisiones las tome yo". El adultocentrismo se produce porque los adultos no cuentan con las herramientas suficientes en su propia vida para orientar y enfrentar lo que están viviendo los más jóvenes en su época, lo cual genera una especie de conservadurismo: se busca seguir manteniendo el status quo a través del control, bajo el supuesto de que lo que funcionó ayer puede servir hoy para guiar a las y los más jóvenes (Krauskopf, 2000, cit. por UNICEF, 2013, pp. 19-20).

El adultocentrismo se refleja en las prácticas desde las cuales se corrobora la subordinación de las personas jóvenes y se consolida gracias a discursos que definen a la juventud como un grupo social deficiente de razón, de madurez, de responsabilidad y/o seriedad. Dichos estereotipos ratifican el orden de cosas en el que se niega la posibilidad de transgresión: no importa lo que la edad social adolescente haga, siempre estará por debajo del conocimiento y experiencia adulta (Vásquez, 2013, p. 222).

La adolescencia precisa ser moldeada, educada y es menester que se apegue a los roles establecidos para su edad y género, pero también es una etapa de aprendizaje, una etapa de cambio que puede ser considerada como un momento fundamental para la creación de nuevas opciones de convivencia (Rodríguez, 2000, p. 114) con la posibilidad de romper con los esquemas tradicionales que atan tanto a mujeres como hombres a reproducir esquemas marcados por la desigualdad (Montesinos 2002, cit. por Martínez y Solís, 2009, p.160).

El surgimiento de los derechos de la niñez y adolescencia alteraron el orden de superioridad de los adultos, proponiendo relaciones más igualitarias. Desde mediados del siglo XX y lo que va del siglo XXI, se han articulado varios cambios: la figura de la madre dejó de ser el único modelo a seguir para las mujeres; los roles de género han sufrido un cuestionamiento desde sus mismos cimientos; los derechos del niño fijaron normas de crianza basadas en el respeto a la dignidad de los niños, niñas y adolescentes, anatemizando la educación basada en el castigo físico (considerada "normal”). Estos y otros fenómenos, en los distintos giros que han tomado, han disminuido, acotándolos, la autoridad y el poder de los adultos (UNICEF, 2013).

Los cambios sociales y culturales respecto a la adolescencia han sido y son (en presente) difíciles de asimilar para las personas adultas, porque implican una reestructuración de los roles adulto/adolescente y el derrocamiento de un modelo de conducta aprendido. Una y otra vez, durante las entrevistas que realicé como investigadora, surgió un mismo lamento entre las y los adolescentes: la incomprensión 
generalizada del mundo adulto; sin embargo, las y los adultos opinan lo mismo: la juventud no comprende que lo hacen por su bien, porque desean lo mejor para ellos (UNICEF, 2013).

La época actual demanda la creación de nuevos modelos de ser adulto y nuevas formas de relación con las y los adolescentes. A este nuevo modelo se le denomina “adulto aliado", y propugna el reconocimiento de las y los adolescentes como un verdadero otro; desde esa base, busca educar y co-aprender con las y los adolescentes para trabajar el conocimiento de sus límites sin anular su personalidad; de esta forma se promueve el crecimiento saludable y el ejercicio de los derechos en forma responsable (UNICEF, 2013).

En la adolescencia, la persona tiende a cuestionar las opiniones y exigencias del mundo adulto, manifiesta oposición frente a las reglas y normas impuestas tanto por la familia como por la sociedad; dicha oposición y etapa de cuestionamiento, si es bien guiada (por un adulto aliado), puede conducir a una reflexión crítica sobre los roles de género, que brindará la apertura necesaria para romper el ciclo de reproducción de violencia y discriminación de género (Álvarez, 2003, p. 98). Un/una adolescente, debido a su juventud, aún no tiene cimentados los roles de género como los tiene una persona adulta, por lo cual presenta mayor apertura al aprendizaje y tiene mayores deseos de forjar un mundo mejor (o al menos para sí misma/o), lo cual brinda la posibilidad de abrir caminos que guíen a la construcción de una sociedad más equitativa. Como menciona Álvarez (2003): “es importante estudiar la violencia de género para poder prevenirla en todos los sectores de la población, con especial interés a las y los adolescentes porque en muchas ocasiones se convierten en víctimas de la violencia por desconocimiento o falta de preparación" (p. 98).

La adolescencia se puede conceptualizar como una etapa de afinación con respecto a creencias y prácticas en torno al noviazgo, lo cual repercutirá en la vida futura. Tal como considera Rojas (2013), "es una etapa de preparación y ensayo de habilidades para el noviazgo en la adultez joven" (p. 50). La adolescencia puede verse como una etapa en la que las y los adolescentes están explorando su entorno social y dichas vivencias repercutirán en su conceptualización de cómo funciona, principalmente en lo que concierne a las relaciones de pareja. En esta etapa, como observa Álvarez (2003): “es difícil que los sujetos se identifiquen a sí mismos como posibles víctimas o victimarios de la violencia de género; lo cual se debe a la naturalización de la misma, la cual poco a poco va convirtiéndose en parte de la cotidianidad, mecanizándose tanto la conducta del agresor como de la víctima" (pp. 98-99). 


\section{AMOR, NOVIAZGO Y VIOLENCIA}

Las relaciones de noviazgo tienen relevancia en todas las etapas de la vida; sin embargo, es en la adolescencia cuando empiezan a explorarse: el acercamiento al sexo opuesto, el noviazgo y la afinación de los roles de género se conjugan, por lo cual es importante comprender cómo conciben y viven las relaciones de pareja las y los adolescentes.

En la adolescencia y la edad adulta, el noviazgo implica significados y prácticas diferentes, puesto que la primera de estas etapas es de aprendizaje y exploración, motivo por el cual los roles de género están menos consolidados, se tiene mayor apertura y la duración de las relaciones de pareja tienden ser más cortas; en cambio, en la etapa adulta se cuenta con mayor experiencia, los roles de género están más consolidados (lo cual no implica que no puedan resignificarse, pero es más difícil) y existe la exigencia social de que las relaciones sean más largas, lo cual se interpreta como estabilidad y madurez (aunque no necesariamente sea así). De tal modo y para un mejor análisis, la adolescencia debe ser estudiada en sus propios términos. Por ello también es primordial estudiar la violencia de género en el noviazgo, pues se explora la dinámica de dominación y poder en una etapa del desarrollo diferente a la adulta (Mulford y Giordano, 2008, cit. por Rojas, 2013, p. 51).

Para entender el fenómeno de la violencia de género en el noviazgo adolescente, propongo que profundicemos primero en dicho concepto. Se entiende como cualquier acción o conducta basada en el género que cause muerte, daño o sufrimiento físico, sexual o psicológico a la mujer o al hombre, a través de mecanismos de violencia físicos y/o psicológicos (Pereira, 2012, pp. 55-56), tanto en el ámbito público como privado. La violencia más perceptible es la violencia física: empujones, tirones de cabello, bofetadas, golpes, patadas (Barragán, 2006, pp. 33-34), ya que provoca daños perceptibles; a ésta le sigue la violencia psicológica, la cual incluye conductas que buscan menoscabar el autoconcepto ${ }^{3}$ de la pareja: amenazas, bromas hirientes, insultos, chantaje, etc. En la violencia psicológica existe una modalidad menos perceptible: la violencia simbólica.

La violencia simbólica, definida por el sociólogo Pierre Bourdieu como "una violencia invisible ejercida a través de los caminos simbólicos de la comunicación y el conocimiento o, más exactamente, del desconocimiento, del reconocimiento o, en último término, del sentimiento" (Bourdieu, 2015, pp. 12-13). Es parte de la conducta

\footnotetext{
${ }^{3}$ Percepción que tiene la persona de sí misma: virtudes y defectos, fortalezas y debilidades.
} 
humana, tiene diversos significados y se despliega para cumplir determinados fines. Aunque existen otros tipos de violencia: económica, sexual, política, espiritual, etc. (Barragán, 2006, pp. 33-34), solo abundaré aquí sobre la violencia física y psicológica, incluida en ésta última la violencia simbólica, toda vez que las y los adolescentes que colaboraron en un estudio más amplio ${ }^{4}$ no señalaron, o yo no percibí, la presencia de otros tipos de violencia.

La violencia de género afecta a la sociedad porque pone en peligro la salud de las personas involucradas, reduce o hace más rígidas las defensas psíquicas, incrementa las enfermedades existentes y limita las capacidades de participación en los grupos sociales a los que la persona pertenece. En ocasiones es imperceptible y está estructurada sobre una base de aceptación y promoción y autorización histórico-social del maltrato (Álvarez, 2003, p. 98). La violencia envuelta en la cotidianidad se vuelve imperceptible, despersonalizada y no se le da un espacio de análisis en la conciencia individual ni colectiva; se trata de una realidad compleja que la sociedad se resiste a percibir y pensar de forma escrupulosa (Artiles 2000, cit. por Álvarez, 2003, p. 98).

La violencia simbólica se manifiesta a través de conductas encubiertas, como los celos, la manipulación sutil, el aislamiento de la pareja, la vigilancia como manifestación de amor; está en el discurso que genera una multiplicidad de prácticas. En general, la violencia de género constituye un instrumento de control, dominio y sometimiento que busca imponer las pautas de comportamiento que un género debe respetar, y mantener un sistema de conductas consideradas naturales. No tiene como fin hacer daño en sí mismo, sino ejercer dominio y mantener así la desigualdad, imponiendo un modelo de relación de pareja asimétrico, que otorga poder y privilegios al agente de la violencia, en consonancia con lo que se ha aprendido sobre cómo debe funcionar una pareja (Paz y Fernández, 2014, pp.11-12).

\section{CiClO DE LA ViOLENCIA EN EL NOVIAZGO}

Como se ha visto, la violencia de género se caracteriza por su habitualidad, lo cual significa que no ocurre en episodios aislados: los comportamientos de dominio, coacción, agresión, celos, control, etc., se mantienen a lo largo del tiempo. La violencia se manifiesta de forma intermitente en tres etapas:

4 Tesis de Maestría en Ciencias Sociales (Instituto de Investigaciones Histórico-Sociales, Universidad Veracruzana) 


\section{Primera etapa: Acumulación de tensión}

Esta fase se caracteriza por cambios repentinos/imprevistos en el estado de ánimo de él, debido a cualquier problema de conveniencia, es decir, él puede reaccionar de forma agresiva frente a eventos incómodos o de frustración, si ella no cumple con las expectativas y/o exigencias, si ella no cede a la dominación o no de la forma esperada.

La adolescente busca controlar la situación de forma pasiva (en consonancia con la construcción de su identidad de género), con comportamientos que, según ha aprendido, resultan útiles: ser condescendiente, ceder ante las demandas de la pareja, intentar satisfacer e incluso anticipar sus deseos o caprichos; procurar no hacer nada que le desagrade y procurar conductas que le agraden; incluso puede justificarlo (con otras personas y consigo misma), pensado que reacciona así porque tiene problemas, viene de una familia difícil, no sabe manejar sus sentimientos/emociones, etc.

En esta etapa, la adolescente minimiza las conductas de él ("no fue para tanto", "lo que pasa es que no sabía”, "todos cometemos errores”) para justificarlas y delegar la responsabilidad de sus acciones a causas externas ("tiene problemas", "debe ser porque estaba estresado”). Todo ello como un “mecanismo de autodefensa” para no reconocer los problemas y continuar la relación de pareja con la esperanza de que cambie la situación (Paz y Fernández, 2014, pp. 13-14).

\section{Segunda etapa: Explosión de violencia}

Se descarga la tensión acumulada en la fase anterior. No sólo debe pensarse en la agresión física como forma de explosión o descarga, ya que existen otras manifestaciones de explosión masculina, como gritar, ignorar, golpear muebles, amenazar con el rompimiento de la relación, humillar, prohibir ciertas conductas de forma explícita, etc. El móvil de la explosión es castigar los comportamientos de la pareja que el otro considera inadecuados, desde su planteamiento de poder y desigualdad; su finalidad no es causarle daño, sino lograr que ella "aprenda la lección" y "se porte bien" (Paz y Fernández, 2014, p. 14).

La adolescente vive el enfado de su pareja con confusión e incluso puede sentirse vulnerable porque la culpe de la explosión: "si hubieras hecho lo que te pedí, esto no habría pasado”. También él puede justificar su comportamiento, alegando causas externas: "estaba tomado" o a factores externos estresantes, tratando de excusarse ante ella. Una vez finalizada la descarga de violencia, ella quedara en un estado de conmoción 
y bloqueo, porque ¿cómo alguien que la ama actúa así?, sin querer creer lo que ha pasado, minimizando el ataque e incluso negando lo que acaba de ocurrir (Paz y Fernández, 2014, pp. 14-15).

\section{Tercera etapa: Luna de miel}

Es una fase de manipulación afectiva, que se caracteriza por la disminución de la tensión. Puede adoptar diferentes formas: él puede pedir perdón y prometer no volver a hacerlo, reconocer la culpa y plantear cambios (incluso reconocer que necesita ayuda). Puede apelar a características femeninas (adolescente cuidadora) para hacerle saber que la necesita, que sin ella no podría seguir, para evitar el abandono (Paz y Fernández, 2014, p.15).

Durante la fase de explosión él ejerce el castigo ("necesario" para que ella elimine o desarrolle comportamientos que él espera); sin embargo, sabe que no puede ejercer la violencia de forma continuada porque ella tendería a asumir conductas de evitación o escape, dejando la relación; por ello, tras el castigo, adopta conductas de manipulación afectiva, es decir, se vuelve cariñoso, detallista, romántico, etc., para que ella continúe en la relación. Entonces la victimización de la adolescente se hace más profunda, pues se estrecha la relación de dependencia. Si había decidido abandonar la relación, en esta etapa y bajo dichas conductas asumidas por él, ella considera continuar porque él está arrepentido y cambiará. Su construcción femenina contribuye a que ella crea, tenga esperanza en el cambio. Incluso puede no dejarlo porque él la necesita y como mujer siente que "debe cuidarlo" (Paz y Fernández, 2014, p.15).

El hecho de que la adolescente continúe la relación puede generarle conflictos con amistades que no están de acuerdo con su situación, y aislarla de personas cercanas. No suele haber un final claro en esta fase: la acumulación de tensión reaparece alternativamente, con momentos románticos entremezclados con peleas, hasta que la fase de explosión sucede y así se repite el ciclo (Paz y Fernández, 2014, p.15).

En cuanto al aspecto educativo, AUGE (Desarrollo Autogestionario. A.C., 2015) señala que en México ha habido un incremento, aunque mínimo, en el ingreso a la educación; las becas del programa Prospera han resultado un incentivo económico que retiene a los estudiantes en la escuela; sin embargo, ello no elimina el hecho de que gran parte de las niñas y los niños no continúa sus estudios más allá de la secundaria o preparatoria. Desde un enfoque de género, de acuerdo con las estadísticas señalas por el Centro de Información Estadística y Geográfica del Estado de Veracruz (CEIEGVER, 
2014-2015), de un total de 4005 estudiantes inscritos en educación especial, primaria, secundaria, bachillerato, educación para adultos y formación para el trabajo en Teocelo, 2063 son hombres y 1,942 mujeres.

La calidad de la educación deja mucho que desear y el contenido curricular resulta poco relevante para las y los jóvenes, debido a que mucho de lo que se ve en el aula no tiene cabida en su realidad social; si a ello se añade las precariedades económicas, tenemos el marco perfecto para el abandono escolar y una entrada precoz al mundo adulto, ya sea para trabajar o vivir en pareja, dos procesos naturalmente vinculados (AUGE, 2015).

Indicadores de 2010, que parecen ser los más recientes, señalan que el 63.3\% de la población vive en situación de pobreza, y con ello en alto grado de marginalidad. De acuerdo con el Consejo Nacional de Evaluación de la Política de Desarrollo Social (CONEVAL), el 11\% de la población vive en pobreza extrema y el 26.1\% es vulnerable por carencias sociales (Plan Municipal de Desarrollo, Teocelo, 2014, pp. 75-78).

En otros datos, la mayor parte de la población cuenta con luz eléctrica y una llave de agua dentro o fuera de la casa; sin embargo, en las comunidades con alto grado de marginación (pisos de tierra y techos de láminas de cartón) no se cuenta con los servicios sanitarios adecuados; en general escasean los caminos pavimentados y la calidad de los servicios: agua, salud, educación y transporte, puede calificarse como deficiente, por las distancias, la falta de personal de salud, la insuficiencia de medicamentos y el ausentismo de las y los docentes (AUGE, 2015).

\section{SER MUJER EN TEOCELO, VERACRUZ}

En 2012, el ayuntamiento de Teocelo, a través del Instituto Municipal de la Mujer, elaboró un diagnóstico cualitativo y cuantitativo sobre la situación de mujeres y varones en cada comunidad; diagnóstico que surgió de la experiencia del programa "Construyendo equidad de género". 5 Este documento echa luz sobre un sinnúmero de asimetrías; entre ellas, el hecho de que Las mujeres tienen menos oportunidades laborales que los varones: se encuentran segregadas de la estructura ocupacional, sobre todo en el medio rural; tienen un lugar secundario respecto a las actividades económicas: para el varón casi siempre fungen como meros auxiliares. No es de sorprender que las diferencias de

\footnotetext{
${ }^{5}$ Instituto Municipal de la Mujer de Teocelo (2012). Diagnóstico de la situación de las mujeres en el municipio de Teocelo, Veracruz. Recuperado de: http: //cedoc.inmujeres.gob.mx/fodeimm/Teocelo_Dx_2012.pdf
} 
ingreso entre varones y mujeres sean altamente significativas a lo largo y ancho del municipio.

Es importante destacar la dependencia económica de las mujeres, porque repercute negativamente en otros ámbitos de la cotidianidad: se ha demostrado una y otra vez que situaciones de violencia se tornan recurrentes en contextos de escasa autonomía económica. Por supuesto, a ello habría que añadir una narrativa machista, completamente naturalizada, en la cual las mujeres son las cuidadoras del hogar por excelencia, lo cual les demanda gran parte de su tiempo. Para ellas resulta extremadamente difícil acceder al mundo laboral, y eso provoca que vivan una situación de dependencia que limita su pleno desarrollo y las hace tolerar golpes, y/o violencia económica, todo ello porque perciben que no tienen más opción que tolerar la situación "que les tocó vivir".

Las mujeres enfrentan a problemáticas diversas; entre otras, falta de empleos remunerados, oportunidades muy limitadas de educarse, dependencia de la pareja, escrúpulos ante el uso de anticonceptivos, principalmente por la ideología religiosa que aún pesa sobre ellas. Lamentablemente, dichas situaciones no son aisladas; forman parte de una violencia estructural que limita las posibilidades para el desarrollo de las mujeres.

Ahora bien, pese a que los niveles de violencia doméstica son altos en el municipio, hay un bajo índice de denuncias. Sucede con mucha frecuencia que las mujeres no se atrevan a demandar a sus esposos por miedo a las represalias (las amenazas tienen que ver con quitarle a sus hijos o demandarlas por adulterio y abandono de hogar, o incluso que la demanda no proceda y encontrarse en un riesgo mayor). Las mujeres se muestran desconfiadas ante las acciones de las autoridades para garantizar sus derechos; la experiencia les ha enseñado que frente a la denuncia se sufre de negligencia e impericia.

La subordinación de las mujeres, las desigualdades a las que están expuestas, la violencia que viven, y de la cual difícilmente logran sobreponerse, sólo puede explicarse a través del género, categoría que se utiliza para señalar la jerarquización sobre la mujer. En palabras de Cayeros (2010, cit. por Hernández, Alberti, Pérez, Pérez, Olivera y Talavera, 2014, p. 119): la construcción de la identidad femenina y masculina está determinada por el sistema sexo-género patriarcal en el cual los atributos femeninos están subordinados a los masculinos, es decir, son socialmente de mayor valor las características masculinas (trabajo) que las femeninas (labores domésticas).

La violencia de género, pues, es un fenómeno común en todos los ámbitos de la vida social. Tiene rostros diferentes en cada contexto, pero siempre está presente. Es una práctica que todos, mujeres y hombres, reproducimos de diversas formas. Si a ello le 
agregamos el escenario de violencia que el contexto proporciona, la situación se llena de matices y puntos de inflexión. La violencia estructural provoca la emergencia de fenómenos complejos respecto a cómo se asumen el género y el amor.

Aterrizando lo anterior en historias recopiladas en Teocelo, quisiera mencionar la situación de la madre de un adolescente, que se acercó a mí para consultarme (soy psicóloga) una situación sobre la cual no sabía qué hacer. Terminó contándome su historia: desde pequeña (8 años), en su casa se hacía cargo de las labores domésticas: limpiaba, lavaba la ropa de las y los integrantes de la familia, hacía de comer, y años más tarde (ya tenía 14 años), para salir de la situación de su hogar, decidió vivir con su pareja, quien, aunque al principio era amable, al poco tiempo de vivir juntos la empezó a golpear. Fueron más de 12 años los que ella vivió violencia física (golpes), violencia económica (él no daba dinero para el sustento familiar o daba lo mínimo, el resto lo gastaba en alcohol), violencia psicológica (le decía que iba a estar sola, que sin él no era nada, que nunca iba a salir adelante) y violencia sexual (la obligaba a tener relaciones sexuales); a ello había que agregar que él era alcohólico.

La violencia estructural se refleja en la marginación y pobreza extrema que ella vivía: la dependencia económica hacia su pareja, su nulo acceso a la educación y que cuando acudió al Sistema para el Desarrollo Integral para la Familia (DIF), su versión del abuso sexual que padecía fue puesta en duda, porque "un hombre tomado no tiene la fuerza para abusar sexualmente de alguien). Ante ello surge la pregunta: ¿por qué no dejó a su pareja antes? La respuesta está en los diversos elementos previamente mencionados y no en una causa única. Lo que pretendo explicar con este breve relato es la influencia del espacio sociodemográfico en la construcción del género y crear una base para explicar, más adelante, la violencia presente en el noviazgo entre las y los adolescentes.

\section{RURALIDAD Y VIOLENCIA}

Cada adolescente construye subjetivamente su identidad de acuerdo con su entorno social, familia, escuela, influencia de los medios de comunicación, etc. (Gutiérrez, 2015, pp. 33-34); por tal motivo, el conocimiento del contexto espacial es crucial para entender la vida cotidiana de las y los adolescentes; no es lo mismo ser adolescente en un entorno rural y estar sujeto a carencias económicas, menor acceso a la educación y a desigualdades sociales de diversa índole, que serlo en un contexto urbano, donde el acceso a todo tipo de recursos es sensiblemente mayor. 
El hecho de que el $11 \%$ de la población de Teocelo viva en pobreza extrema y el 26.1\% sea vulnerable debido a carencias sociales (CONEVAL, cit. por Plan Municipal de Desarrollo, Teocelo, 2014), además de padecer una baja calidad en la educación, propicia que un buen porcentaje de las y los jóvenes dejen sus estudios para incursionar en el mundo laboral y, muy pronto, vivir en pareja, ya que son dos procesos naturalmente vinculados, que marcan la entrada precoz al mundo adulto (AUGE, 2015).

Existe represión hacia las y los adolescentes mediante la promoción de la abstinencia premarital, donde la familia cumple un papel central desde la crianza; dicha represión se lleva a cabo a través de producciones simbólicas y regulaciones morales sobre la sexualidad cuyo control ha cambiado a causa de la urbanización; sin embargo, aún hay muchos tabúes (Rodríguez y Keijzer, 2002), principalmente en las comunidades rurales.

De acuerdo con Censo de Población y Vivienda (2010), el 0.06\% de las niñas de 12 años de edad, ha tenido al menos un hijo. La información que reciben las y los jóvenes rurales sobre sexualidad y reproducción está altamente influida por valores tradicionales de género que orientan el papel de madre y esposa para las jóvenes y de proveedor para los hombres (Hernández, Alberti, Pérez, Pérez, Olivera y Talavera, 2014, p.116).

La juventud rural es uno de los sectores sociodemográficos con mayor exclusión social y, en consecuencia, con menores posibilidades de desarrollo (Durston 2001, cit. por Márquez, 2014, p. 3), debido a causas como: a) una fuerte dominación y discriminación por persistencia de las estructuras patriarcales; b) sobrecarga de trabajo doméstico no valorado; c) baja calidad de la oferta educativa; d) falta de acceso a la educación sexual y reproductiva, y e) violencia familiar (Márquez, 2014). Estos elementos conjugados sitúan a la adolescencia rural en condición vulnerable.

Las acciones dirigidas a adolescencia y juventud, cuando existen, se centran en temas de salud sexual y reproductiva: maternidad adolescente e infecciones de transmisión sexual, y, aunque son temas relevantes, se invisibiliza el tema de salud desde una perspectiva más amplia y holística (Ullman, 2015), que tomaría en cuenta factores como el placer sexual, la dependencia en las relaciones de pareja, el miedo a la soledad, así como problemáticas familiares y su influencia en las relaciones amorosas, etc.

La forma como experimenta la sexualidad cada hombre y cada mujer pasa por momentos de obediencia y rebeldía influenciados por sistemas de parentesco y noviazgo con reglas de herencia, matrimonio y divorcio; de división del trabajo, normas religiosas, familiares y escolares, que se van transformando para redefinir las libertades sexuales y extender su ejercicio (Rodríguez, 1994 cit. por Hernández, Alberti, Pérez, Pérez, 
Olivera y Talavera, 2014, pp. 118-119).

De acuerdo con la información recabada de Teocelo, aún persiste la tradición de que los adolescentes (varones) en compañía de sus padres asistan a la casa de la novia con el fin de pedir permiso para establecer una relación de noviazgo. Incluso existe la tradición de "devolver el permiso", es decir, si la relación de noviazgo termina, los adolescentes deben avisar a los papás de la novia. Los lugares a los que frecuentemente salen las y los adolescentes a pasear con sus amigos/pareja son el parque y el campo. Es necesario que ellos vayan por ellas a sus casas y después las regresen para que estén sanas y salvas.

Por lo que pude observar, el noviazgo a temprana edad es común, es decir, desde los 11 o 12 años, la población adolescente ya establece relaciones de noviazgo, aunque hay familias que los considera muy pequeños y piensan que deben esperar a la vida adulta para tener pareja (sin importar que sólo se trate de un noviazgo). En el proceso de cortejo, son los adolescentes quienes deben tomar la iniciativa, y las adolescentes tienen el poder de decir "si”" o "no". Según uno de los entrevistados, "es necesario tener dinero para invitar a una chica a salir".

De acuerdo con la Encuesta Nacional sobre Violencia en el Noviazgo (ENVINOV, 2007, cit. por IMJUVE, 2008), el 13.2\% de los jóvenes rurales ha experimentado al menos un incidente de violencia física durante su noviazgo, mientras que el $74.7 \%$ ha sufrido violencia psicológica. Según datos del Fondo de las Naciones Unidas para la Infancia (UNICEF, 2016), en América Latina y en el Caribe, la edad para la unión conyugal es más baja entre las poblaciones rurales que en las zonas urbanas; incluso a nivel mundial, las mujeres de las áreas rurales tienden a casarse más jóvenes. La adolescencia rural se perfila como una población vulnerable, y resulta indispensable estudiar sus características para entender los mecanismos de género presentes en las relaciones de noviazgo que desencadenan la violencia.

\section{La escuela: Telesecundaria "Profesor Carlos Hernández GómeZ”}

La escuela es un agente socializador que cumple con una importante función normativa. Al ser uno de los ámbitos donde las y los adolescentes pasan al menos seis horas diarias, se configura como un espacio que influye en la conducta consciente e inconsciente del estudiantado; por eso es importante analizar las conductas que allí tienen lugar. La escuela es un lugar en el cual se despliega una riquísima dinámica social: las y los jóvenes intercambian experiencias y vivencias, crean lazos afectivos, tanto de amistad como de 
pareja; comparten ideología con sus pares y aprenden convenciones sociales a través de la socialización (Martínez y Solís, 2009, p. 166).

La institucionalización escolar se vincula con un conjunto de creencias respecto a lo que cada estudiante "debe” ser. Su principal herramienta es la disciplina, a través de la cual se regula el comportamiento estudiantil y se somete al castigo a aquellas y aquellos que no cumplen con las expectativas. Específicamente, la institucionalidad escolar se manifiesta “con la aparición y desarrollo de una serie de creencias, significados y expectativas de cada comunidad escolar, como resultado de la búsqueda de equilibrio entre las exigencias de las políticas educativas en relación con la calidad de la educación, por una parte, y, por otra, sus propias finalidades, expectativas y necesidades, que se concretan en representaciones compartidas por la comunidad" (Suárez, 2010, pp. 185186).

Si se pretende comprender genuinamente a la adolescencia, ésta ha de ser estudiada en sus propios términos, lo que implica situar la mirada en las prácticas y las visiones que las y los actores construyen sobre sí mismos y su entorno; esto es, incorporar en el análisis los aspectos importantes y particulares que ellos mismos enfatizan de sus experiencias. Las y los adolescentes están íntimamente comprometidos en la construcción y determinación de sus propias vidas, las vidas de quienes les rodean y de la sociedad en la que viven (Castro y Sáenz, 2011).

La juventud/adolescencia está siendo construida incesantemente -siempre está siendo alimentada de significados- por los distintos sistemas institucionales, los medios de comunicación, los entornos tecnológicos, otras generaciones, etc., que de alguna manera le trasfieren sus propias relaciones de desigualdad, poder y dominación. Entre dichos sistemas institucionales, uno que cobra relevancia mayúscula es la escuela, ya que constituye un espacio donde las y los adolescentes pasan gran parte de su tiempo. La escuela educa no sólo en el aspecto intelectual, sino también social y culturalmente, y se encarga de reproducir aquellas conductas que se consideran adecuadas, tales como respetar a las mujeres y rechazar el comportamiento que escapa a los estándares, como tomarse de las manos o besarse en el aula (Castro y Sáenz, 2011).

\section{UNA SECUNDARIA RURAL}

Para concluir, cabe señalar que de acuerdo con la Red de Investigación de Educación Rural (RIER, 2014-2016), en México, el 57\% de las secundarias se ubican en comunidades rurales. Y no obstante que en las evaluaciones estandarizadas, nacionales e 
internacionales (Excale, Enlace, Planea, PISA, Terce), los resultados son más bajos en estudiantes que asisten a escuelas urbanas, debemos subrayar que las escuelas rurales tienen peor equipamiento e infraestructura. A esta situación se agregan otras carencias; por ejemplo, el hecho de que las y los docentes rurales no reciban formación para atender al sector joven de la población, la escasez de materiales didácticos y un muy limitado uso y acceso tecnológico (Agencia Informativa Conacyt, 2017). ${ }^{6}$

Se considera que una persona está en rezago educativo cuando al cumplir los quince años no ha concluido la educación básica (primaria y secundaria). Debido al rezago educativo, la persona no está en igualdad de condiciones con los integrantes de su generación que sí la concluyeron, para, por ejemplo, continuar sus estudios, incorporarse de mejor manera al mercado de trabajo y educar a sus hijos, si fuera el caso (Estudios Agrarios, 2010).

Existe una alta incidencia de rezago educativo en las comunidades pequeñas: 79\% de su población de 15 años y más no ha terminado la secundaria; mientras que los porcentajes en las grandes ciudades con más de un millón de habitantes, las personas sin educación básica completa representan 41.3\% de la población de 15 años y más. Sea un centro de población pequeño o numeroso, la proporción de rezago educativo es mayor en mujeres que en hombres (Estudios Agrarios, 2010).

La Telesecundaria "Profesor Carlos Hernández Gómez", en Teocelo, Veracruz, es una institución de reciente creación. El proyecto nació a partir de una iniciativa del profesor Zimri Arellano Hernández, como respuesta al problema de la deserción escolar y el rezago educativo en el nivel de secundaria. Se concibe como un espacio escolar comunitario, económico e incluyente, que brinda oportunidades de ejercer el derecho a la educación de calidad a todos los jóvenes del municipio y de las congregaciones aledañas. La telesecundaria inició labores en agosto de 2016; se inscribieron 36 estudiantes en total para primero y segundo año. Al principio, el director y una maestra impartían clases en espera de que el gobierno del Estado enviara más docentes. Posteriormente, con la llegada de dos maestras, se dividieron los grupos: dos grupos de

${ }^{6}$ Con base a estadísticas del INEE (2012), se estima que de cada mil niños que se inscribieron a la primaria en el ciclo escolar 2001-2002, sólo 438 terminaron la educación media superior (12 años después). Y según los datos del CEIEGVER (2017), de 897 alumnos en secundaria en Teocelo, Veracruz, solo 432 se inscribieron en bachillerato.

${ }^{7}$ Maestro y activista, Carlos Hernández Gómez nació en Teocelo, el 11 de septiembre de1941. Estudio Filosofía y Letras en la Universidad Veracruzana y fue catedrático de la Escuela Preparatoria “Artículo 3 ”" de Xalapa. Participó en el movimiento estudiantil de 1968; derivado de ello, fue perseguido y tuvo que refugiarse en la ciudad de Tlapacoyan, continuando su labor como catedrático. Cinco años después, se trasladó a Martínez de la Torre y fundó la Escuela Nocturna para Trabajadores. En ciertos momentos se alzó como pacificador de los movimientos estudiantiles magisteriales. La sala del Cabildo de Martínez de la Torre, Veracruz, lleva su nombre. 
primer grado y un grupo de segundo. La escuela inició sus labores en instalaciones prestadas, porque su actual inmueble estaba en construcción.

Al ser de reciente creación, la escuela está en proceso de institucionalización, lo cual significa que aún no cuenta con reglas totalmente definidas con respecto a determinadas conductas, tales como tener novio(a) en la escuela, usar teléfono celular, el horario de entrada, qué hacer en caso de violencia escolar (lo cual tal vez explica el grado de violencia que ahí se registra) e incluso qué medidas tomar si las y/o los estudiantes consumen drogas. Por este motivo, dichas conductas pueden desarrollarse sin una respuesta clara por parte del personal académico, lo cual genera mayor confusión y facilita su reproducción.

El caso de esta Telesecundaria es interesante por la enorme cantidad de desafíos que ha tenido que sortear para poder operar. Las instituciones de Veracruz (Secretaría de Educación de Veracruz, Ayuntamiento de Teocelo, Gobierno del Estado) no le proporcionaron ningún apoyo material. El terreno en el que se asienta fue una donación de la familia Hernández Gómez y la construcción de las aulas fue posible gracias a donativos privados y al trabajo de las y los ciudadanos de dicha localidad. La única aportación del gobierno estatal fue proveer docentes. Y aunque las instalaciones no tienen las condiciones óptimas, las y los alumnos acuden a ellas con regularidad, lo que refleja una genuina necesidad educativa de la comunidad.

A la luz de este contexto, donde el gobierno estatal indolente eludió por muchos años responsabilidades constitucionales mínimas, como ofrecer infraestructura educativa, aunque fuera la más austera, se entenderá el enorme desinterés de las autoridades educativas por asumir la capacitación docente sobre problemáticas como la violencia escolar, la violencia de género, que, como en otras muchas instituciones, ha echado raíces en esta Telesecundaria.

\section{REFERENCIAS}

AgENCIA InFORMATIVA CONACYT (2017). Analizan la situación actual de la educación rural en México. Recuperado de: http://newsnet.conacytprensa.mx/index.php/documentos/35403analizan-la-situacio-n-actual-de-la-educacio-n-rural-en-me-xico

Álvarez R., M. (2003). Violencia de género y adolescencia, una propuesta de intervención educativa. Otras miradas, pp. 96-110.

AUGE (Desarrollo Autogestionario. A.C.). (2015). Las y los jóvenes de nuestra región hoy. 
Sistematización y resultados del diagnóstico participativo con jóvenes, docentes y familiares del medio rural, en el marco del proyecto "Jóvenes sembrando su futuro". México.

BARRAGÁn M., F. (2006). Educación, adolescencia y violencia de género: les amours finissent un jour. Revista Otras miradas, pp. 31-53.

Bourdieu, P. (2002). La "juventud" no es más que una palabra. En: Sociología y cultura (pp. 163-173). México: Grijalbo, Conaculta.

. (2015). La dominación masculina. Barcelona: Anagrama.

Castro y SÁEnZ (2011). Juventud, género y sexualidad. En: Género, cultura, discurso y poder (pp. 281-312). México: INAH.

Centro de Información Estadística y Geográfica del Estado de Veracruz (2017). Teocelo, Veracruz, México: Sistema De Información Municipal. Cuadernillos Municipales. Recuperado de: http://ceieg.veracruz.gob.mx/cuadernillos-municipales-2017/

CNDH (2010-2017). Derechos humanos de niñas, niños y adolescentes en México. Recuperado de: www.cndh.org.mx/Ninos_Derechos_Humanos

- (2016). Cartilla de Derechos Sexuales de Adolescentes y Jóvenes. Recuperado de: http://www.cndh.org.mx/sites/all/doc/Programas/VIH/Divulgacion/cartillas/Cartill a-DerechosSexuales-Adolescentes-Jovenes.pdf

Cobo, R. (1995). Género. En: Amorós, C. (Dir.). 10 palabras clave sobre mujer (pp. 55 83). Navarra, España: Editorial Verbo Divino.

Consejo Nacional de Población (COnApo). (2014). Salud sexual y reproductiva. Recuperado de: http://www.promajoven.sep.gob.mx/files/boletines/infografias-salud-sexual-yreproductiva/veracruz.pdf

CONAPO (2014). Las relaciones de pareja, Un enfoque estadístico.

Recuperado de: http://www.conapo.gob.mx/work/models/CONAPO/Resource/1796/1/images/Co municadoDePrensaRelacionesDePareja.pdf

Connell, R. (1997). La organización social de la masculinidad. En: Valdés, T., y Olavarría, J. (Eds.), Masculinidad/es. Poder y crisis (pp. 31-48). Santiago de Chile: Isis Internacional.

Córdova Plaza, R. (2013). Carne, deseo, cultura. Reflexiones antropológicas sobre la sexualidad. México: CONACULTA/IVEC/GEV.

. (2003). Reflexiones teórico-metodológicas en torno al estudio de la sexualidad. México: Revista Mexicana de Sociología, pp. 339-360.

, Pretelín R, J. (2017). El Buñuel. Homoerotismo y cuerpos abyectos en la oscuridad de un cine porno en Veracruz. México: Ítaca.

Gobierno De Teocelo (2014). Plan Municipal de Desarrollo, 2014-2017. México: Gobierno del Estado de Veracruz. 
GuTIÉRREZ, L. (2015). Género, sexualidad y transición subjetiva en México: construcción de la adolescencia femenina en las celebraciones de 15 años. México: Revista Interdisciplinaria de Estudios de Género, pp. 32-53.

Hernández, M., Alberti, P., Pérez, C., Pérez, M., Olivera, A., Talavera, D. (2014). Relaciones, género y sexualidad entre jóvenes rurales de Salinas de Hidalgo, San Luis Potosí, México (pp. 115-130). Universidad Autónoma Indígena de México.

Hernández GonzÁlez, A. ET Al. (2016). Cartilla de Derechos Sexuales de Adolescentes y Jóvenes (pp. 6-21). México: CNDH, Centro Nacional para la Prevención y el Control del VIH, Fundación Mexicana para la Planeación Familiar.

INEGI (2016). Estadísticas a propósito del 14 de febrero, matrimonios y divorcios en México. Recuperado de: http://www.inegi.org.mx/saladeprensa/aproposito/2016/matrimonios2016_0.pdf

Instituto NACiONAl PARA LA Evaluación DE LA EDUCACiÓn (2012). La Educación en México: Estado actual y consideraciones sobre su evaluación. Recuperado de: http://www.senado.gob.mx/comisiones/educacion/reu/docs/presentacion_211112.pdf

IMJUVE, SEDESOL (2014). Programa Nacional de Juventud 2014-2018. México.

, SEP (2008). Encuesta Nacional de Violencia en las relaciones de noviazgo 2007. Resumen ejecutivo. México.

Instituto Municipal de la Mujer de TeOcelo (2012). Diagnóstico de la situación de las mujeres en el municipio de Teocelo, Veracruz. Xalapa: Gobierno del Estado de Veracruz.

LAmAS, M. (Comp.) (2000). Usos, dificultades y posibilidades de la categoría género. En El género: la construcción cultural de la diferencia sexual (pp. 265-302). México: Programa Universitario de Estudios de Género.

LÓPEZ, J.C. (2014). La escuela como institución disciplinaria adultocéntrica: estudio de caso comparativo entre el Colegio Preparatorio de Xalapa y el Instituto Educativo Panamericano (Tesis de Maestría). México: Universidad Veracruzana.

LOZANO, A.J. (2007). La disciplina en la escuela secundaria: significados de alumnos en riesgo de exclusión. Actualidades Investigativas en Educación, 7(3), pp. 1-20.

MárqueZ, R.I. (2014). Perspectiva de los jóvenes de comunidades rurales de México respecto a la educación media superior. México: Revista Iberoamericana de Producción Académica y Gestión Educativa.

MARTíneZ L. C.; Solís D., D. (2009). El entorno escolar y familiar en la construcción de significaciones de género y sexualidad en jóvenes de Guadalajara. Revista de Estudios de Género: La ventana, pp. 146-183.

MARTíneZ Q, L.W. (2007). Romper el silencio ante una violencia de género cotidiana. 
Revista Otras miradas, pp. 169-188.

Mayobre, P. (2006). La formación de la identidad de género una mirada desde la filosofía. En ZaraZAGA, E. ET AL., Educación social e igualdad de género (pp. 21-59). Málaga: Ayuntamiento de Málaga, España.

Organización de las Naciones Unidas (OnU) (2014). México: Desafíos para un desarrollo incluyente (p. 7-39). Oficinas de Coordinación de las Agencias de la ONU.

Papalia, D. E., Feldman, R. D., Martorell, G. (2012). Desarrollo físico y cognoscitivo en la adolescencia. En Desarrollo humano (pp. 352-417). México: McGraw-Hill.

PAZ, R., JUAN, I., FERNÁNDEZ Z., P. (2014). Guía para madres y padres con hijas adolescentes que sufren violencia de género. Andalucía, España: Instituto Andaluz de la Mujer.

PEREIRA R., S. (2012). Violencia contra las mujeres en la relación de pareja: diagnóstico legal desde la perspectiva de género. Revista Casa de la Mujer, pp. 49-67.

RED DE INVESTIGACIÓn DE EDUCACIÓn RuRAL (RIER), CONACYT, 2014-2016. Recuperado de: http://rededucacionrural.mx/

Rodríguez, G., KeIJZER, B. (2002). La noche se hizo para los hombres. Sexualidad en los procesos de cortejo entre jóvenes campesinos y campesinas. México: EDAMEX/Population Council.

Rodríguez M., Y. (2000). La perspectiva de género; un eje básico para la comprensión de la sexualidad de los y las adolescentes. Revista de Estudios de Género: La ventana, 12, pp. 112-146.

RojAS S., J. L. (2013). Violencia en el noviazgo de adolescentes mexicanos: una revisión. Universidad de Salamanca: Revista de Educación y Desarrollo.

SAuCEDO R., C. (2007). Violencia e indisciplina en las escuelas: ¿Cuál es el papel de la psicología? En Violencia ¿Un nuevo estilo de vida? (pp. 81-108). México: Universidad Autónoma de Yucatán.

ScOTT, J. (1990). El género: una categoría útil para el análisis histórico. En LAMAS, M. (Comp.), El género: la construcción cultural de la diferencia sexual México (pp. 265-302). México: UNAM-Programa Universitario de Estudios de Género, Porrúa.

Solís D., D., MARTíneZ L., C. (2014). Género, cuerpo y diversidad cultural: significaciones y prácticas de estudiantes de secundarias públicas en San Luis Potosí. Revista de Estudios de Género: La ventana, pp. 141-177.

SosA, I., ERviti, J., MenKes, K. (2012). Haciendo cuerpos, haciendo género. Un estudio con jóvenes en Cuernavaca. Revista de Estudios de Género: La ventana, IV(3), pp. $255-$ 295.

SuÁrez R., P. (2010). Institucionalización de la institución escolar mediante el cambio en la 
política sobre evaluación, según el decreto 1290 del 2009. Diálogos Educativos, 19, pp. 183-193.

UNICEF (Fondo de las Naciones Unidas para la Infancia) (2013). Superando el adultocentrismo. Santiago de Chile.

. (2016). Las edades mínimas legales y la realización de los derechos de los y las adolescentes. Una revisión de la situación en América Latina y el Caribe. Recuperado de: https: //www.unicef.org/lac/media/6766/file/PDF\%20Edades\%20m\%C3\%ADnimas\%201 egales.pdf

VÁSQUEZ, J. D. (2013). Adultocentrismo y juventud: Aproximaciones foucaulteanas. Sophia. Colección de Filosofía de la Educación, 15, pp. 217-234. 